International Journal of

ENTREPRENEURSHIP

\& SMALL BUSINESS 


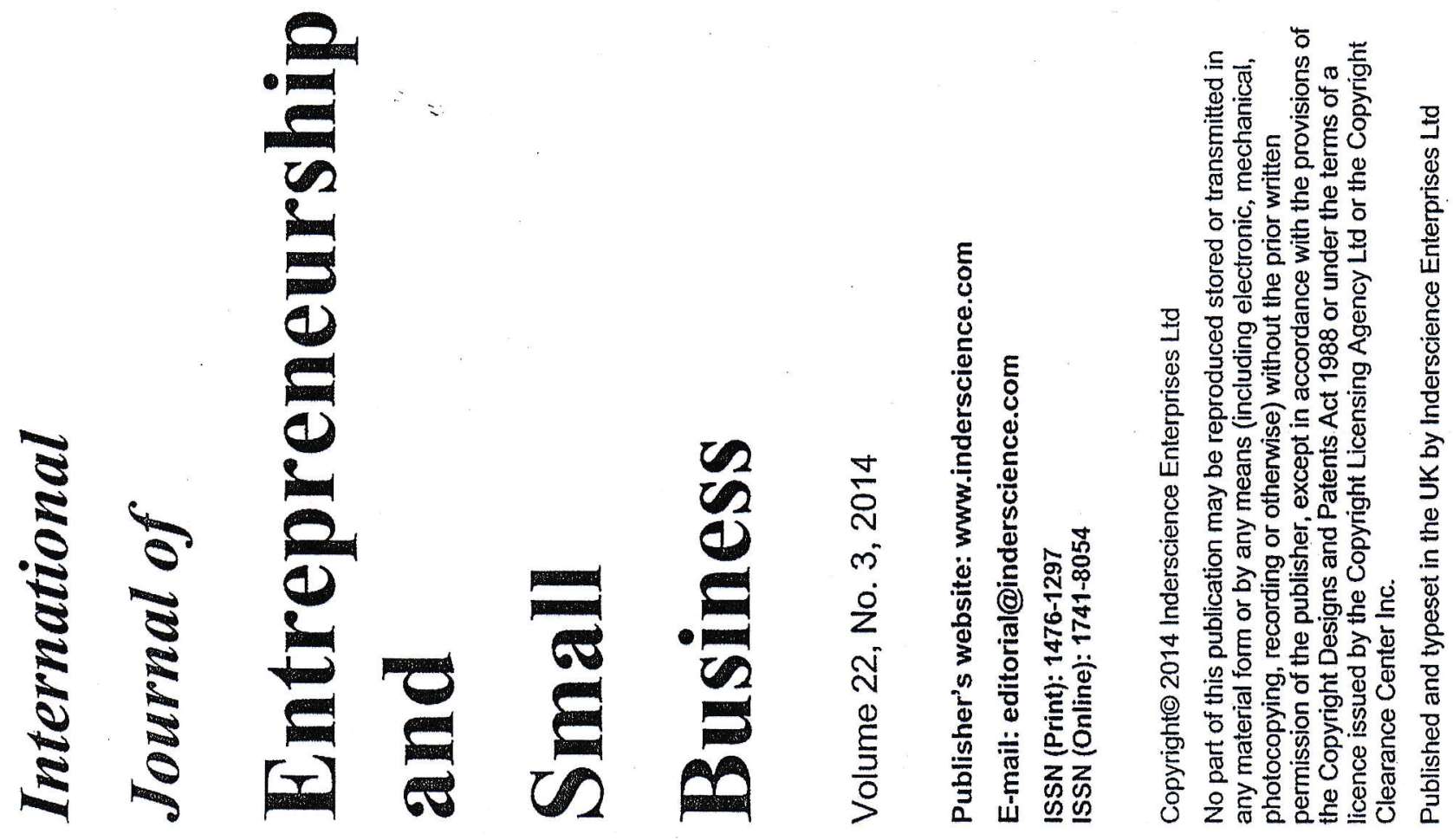



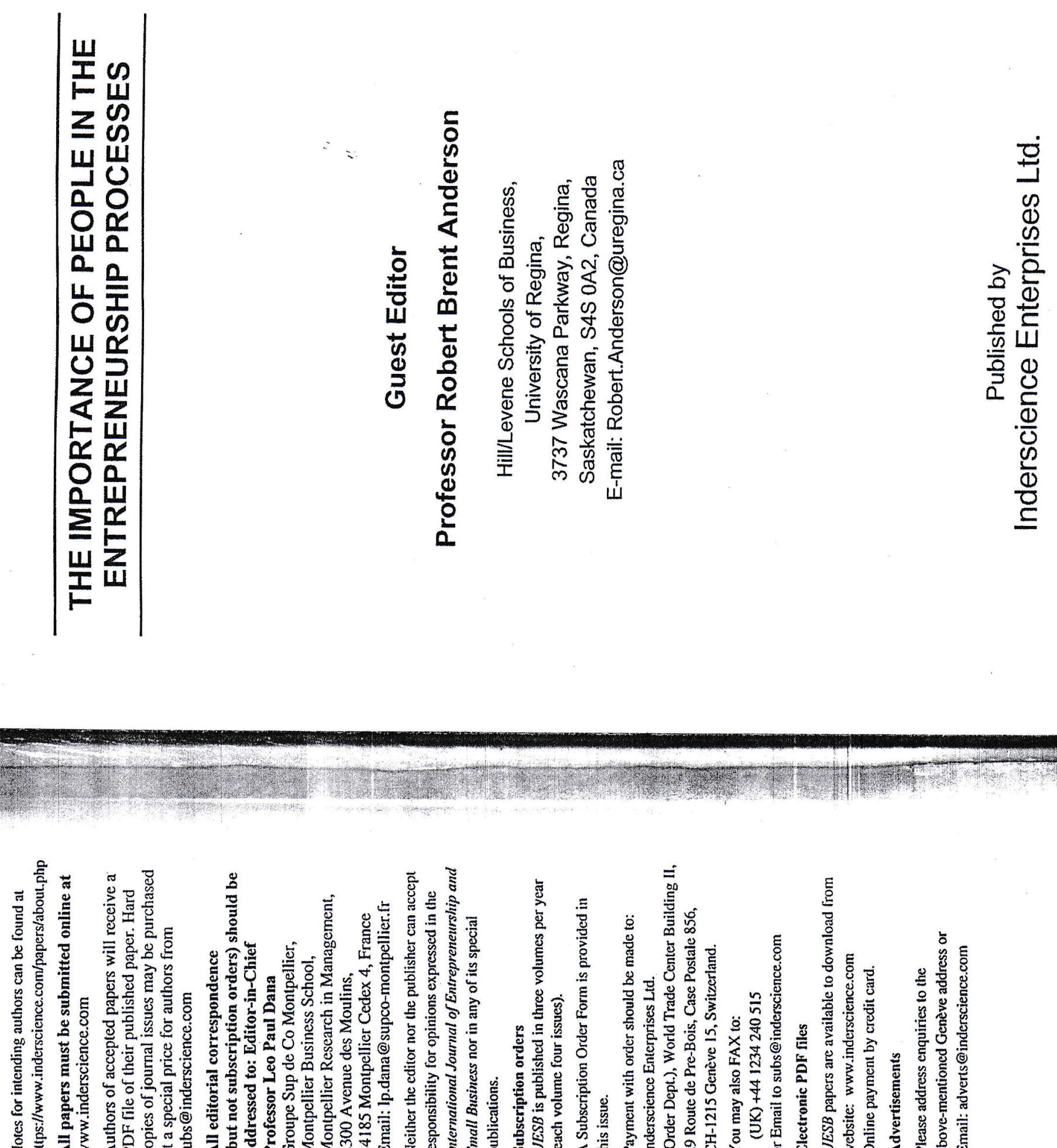

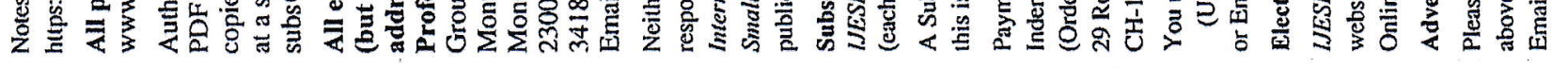

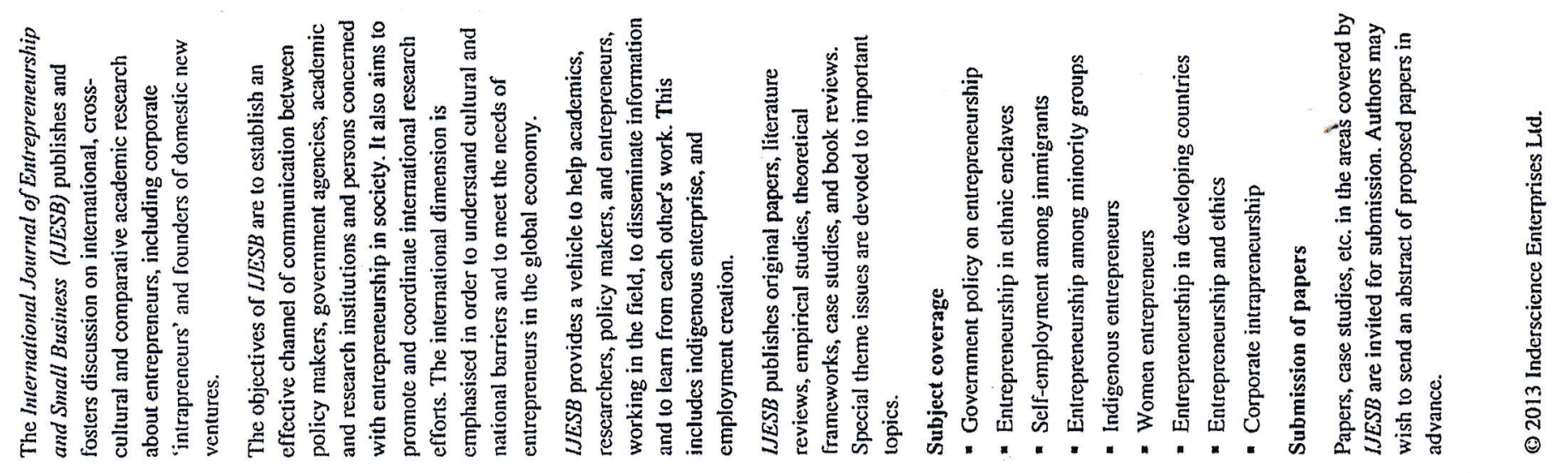



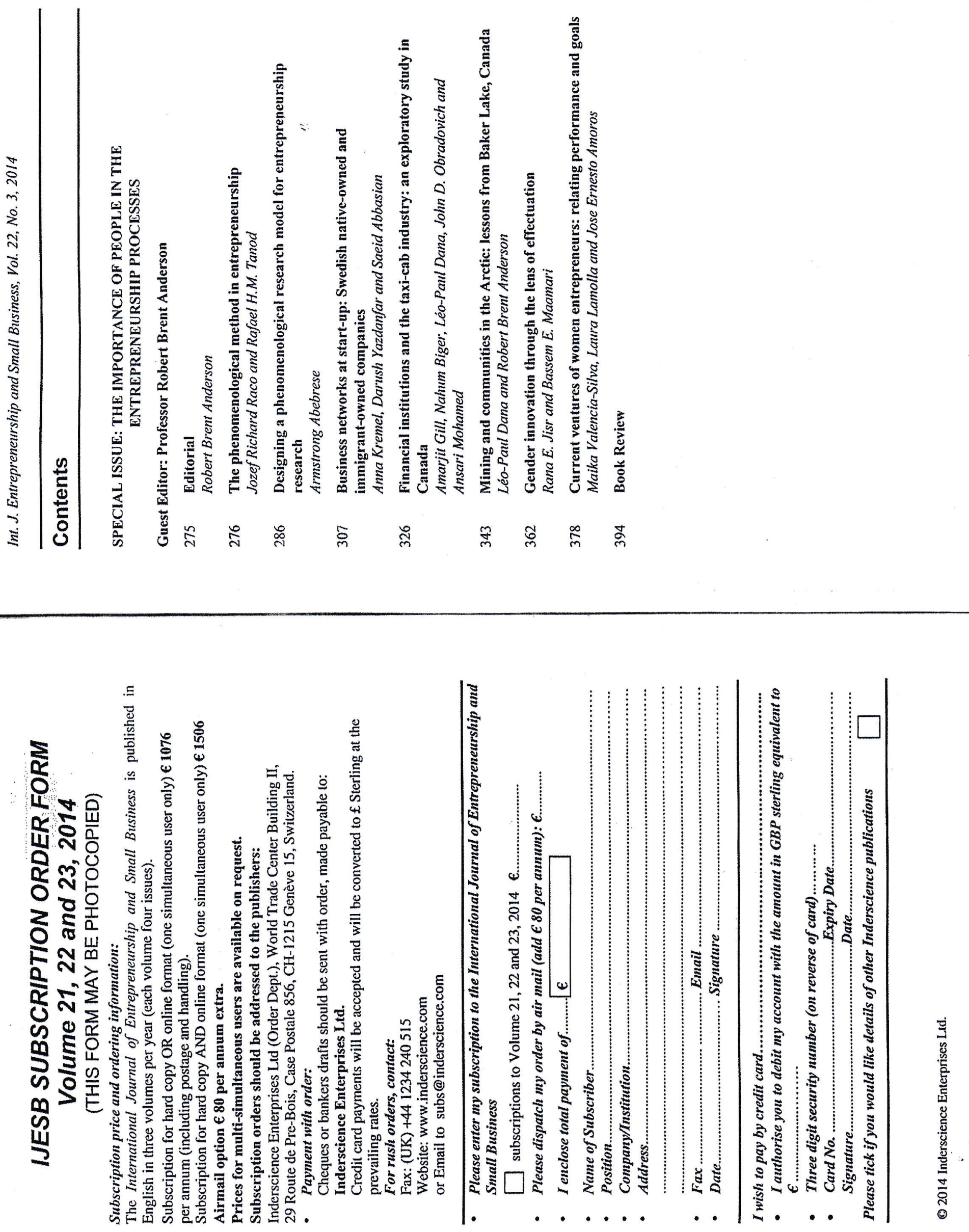

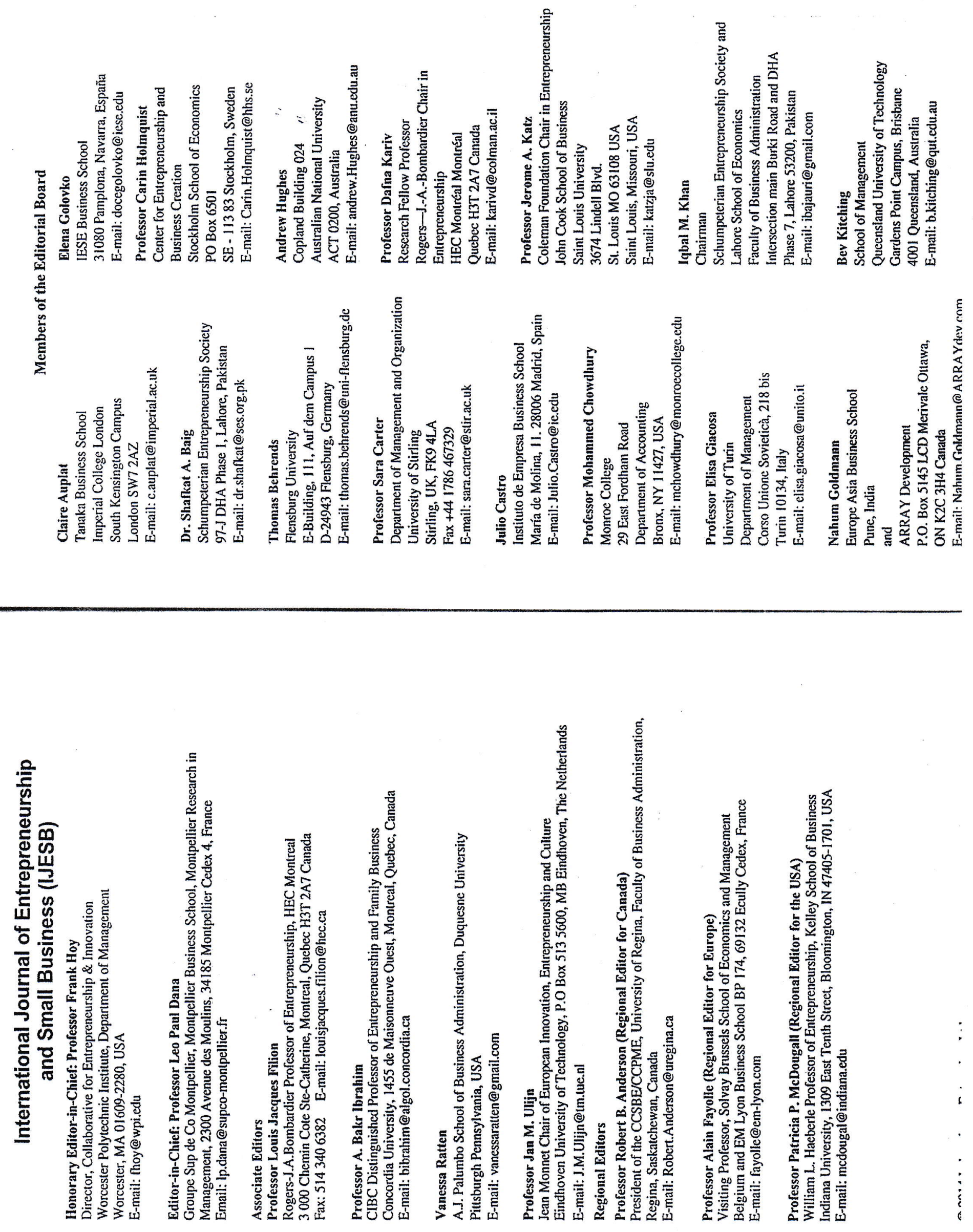


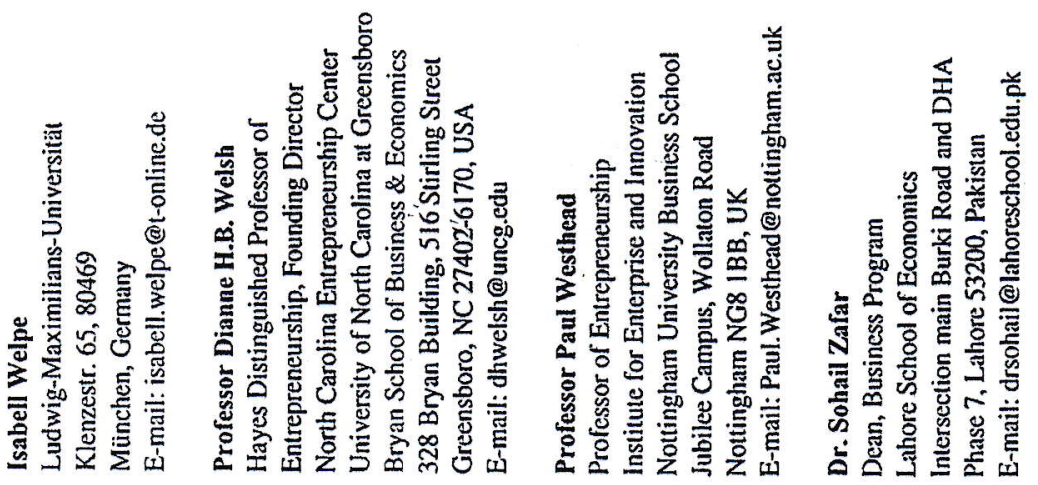

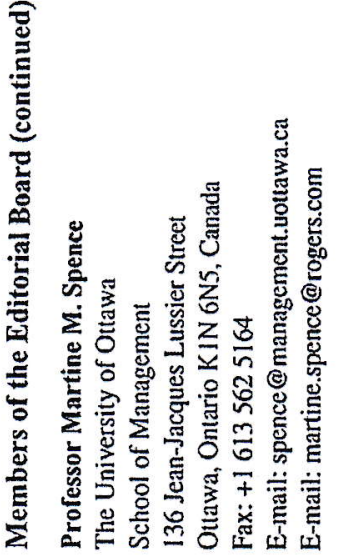
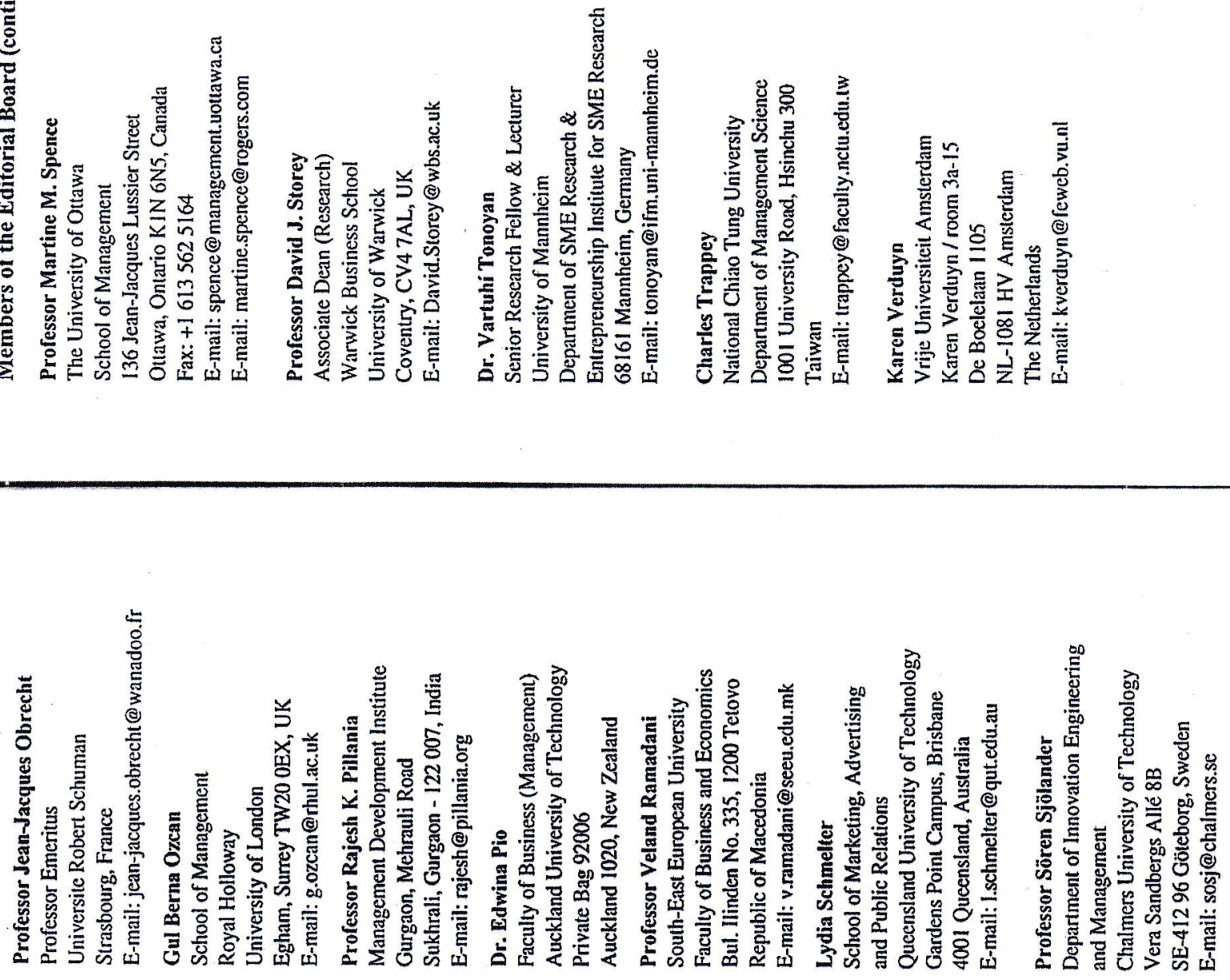

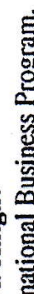

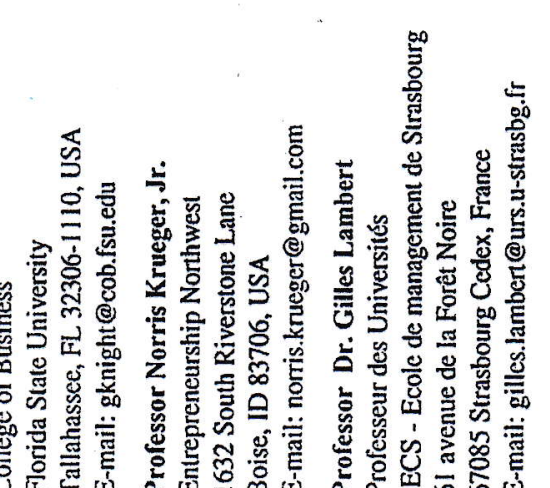

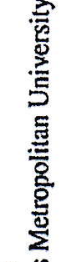

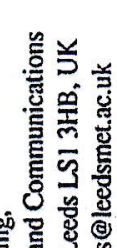

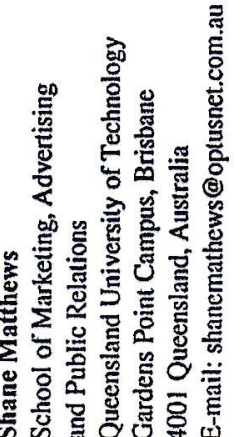

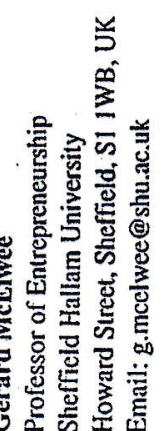

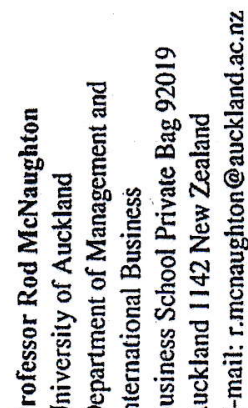

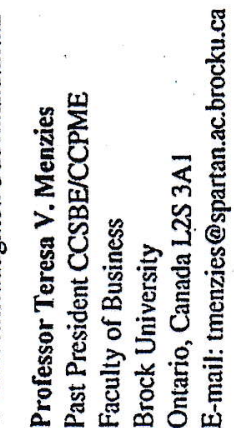




\title{
The phenomenological method in entrepreneurship
}

\section{Jozef Richard Raco* and Rafael H.M. Tanod}

Institute for Research and Development, Universitas Katolik De La Salle Manado-Indonesia, Kombos I Manado 95000, Indonesia

E-mail: revimario@yahoo.com

E-mail: reckyraco@yahoo.com

*Corresponding author

\begin{abstract}
There is a lot of research on entrepreneurship but most of them focus on the external factors of entrepreneurship. Very few researches investigate the internal factors of an entrepreneur such as their own lived experiences. Understanding entrepreneurship means knowing deeper about their concept and meaning about it. The essence of entrepreneurship emerges from the real and true entrepreneurs, those who have their lived experiences. It is in line with the phenomenology, which tries to illuminate and identify through the people's perception. The world and reality has its meaning through a person who experiences it. Every single person has his own concept about the world. It is applied also to entrepreneurship. The meaning itself will drive and motivate an entrepreneur to start a firm. Entrepreneurial activity has a purpose. To uncover the meaning, a researcher should emerge and go deeper to the lived experience of the entrepreneurs and use their stories as the main source of information without any influence and preconceptions of the researcher. In this paper, the writer is going to explain phenomenology as a research method and why it is suitable in doing research on entrepreneurship.
\end{abstract}

Keywords: entrepreneurship; phenomenology; philosophy; qualitative; hypothesis.

Reference to this paper should be made as follows: Raco, J.R. and Tanod, R.H.M. (2014) 'The phenomenological method in entrepreneurship', Int. J. Entrepreneurship and Small Business, Vol. 22, No. 3, pp.276-285.

Biographical notes: Jozef Richard Raco is currently the Chair of Research Center of Universitas Katolik De La Salle Manado. He received his PhD in Educational Management from the State University of Jakarta-Indonesia in 2010. He earned his Master of Science in Business Management from the University of East Anglia UK in 2002, Master's in Economics from the Asian Social Institute of Manila-Philippines, and Bachelor's in Philosophy from the Sacred Heart of Jesus Major Seminary of Pineleng North-Sulawesi Indonesia in 1990. His research interests are entrepreneurship, spirituality and values in management. He is the author of two textbooks in the Indonesian language: The Qualitative Method: Its Varieties, Characteristics, and Excellence (2010); and The Phenomenological Method and its Application to Entrepreneurship (2012) (co-author with Rafael H.M. Tanod).

Rafael H.M. Tanod is currently the Rector of Universitas Katolik De La Salle Manado - Indonesia. His research interests are in education, spirituality and entrepreneurship. He is a PhD candidate at De La Salle University of Manila, Philippines. He received his Master of Arts in Leadership and Management from De La Salle University of Manila, Philippines in 2005, and Bachelor's in 


\begin{abstract}
Management from the Open University of Indonesia. He earned his Bachelor of Arts from the Sacred of Heart of Jesus Major Seminary of Pineleng North-Sulawesi Indonesia in 1993. He is co-author of the text book The Phenomenological Method and Its Application to Entrepreneurship (with Jozef R. Raco) (2012).

This paper is a revised and expanded version of a paper entitled 'Phenomenological method for entrepreneurship' presented at European Council for Small Business and Enterprise (ECSB), Entrepreneurship Education Conference, Helnan Marselis Hotel Aarhus Denmark, 29-31 May 2013.
\end{abstract}

\title{
1 Introduction
}

The importance of entrepreneurship has been widely acknowledged. Drucker (1984) states that entrepreneurship has contributed greatly to the creation of new jobs. Langley (2011) adds that entrepreneurship promotes improved living conditions by providing products and services needed by the society. This has led Djalal (2011), an Indonesian scholar, to claim that if the number of Indonesian entrepreneurs were increased, the poverty of the county could be reduced significantly.

There is a great deal of research conducted on entrepreneurship, including numerous books and articles both online and in print. But most of this research only addresses the external elements of the entrepreneurship; it fails to reveal the essential factors of the entrepreneurship which lay in the deep heart and mind of every single entrepreneur.

The topic of entrepreneurship is relevant not only to of economics or management, but is also emerging as an area of interest in almost all disciplines. However, given the fact that many disciplines have long had an interest in entrepreneurship; academicians have many opportunities to do research on its many rich, complex elements.

Of significant interest is the gap between theories and practices, between classroom discussion and reality in the field. Students who are studying entrepreneurship have no guarantee that they will become successful entrepreneurs, despite having considerable knowledge of the subject. Furthermore, many research findings about entrepreneurship are based on artificial assumptions setup a priori by the researchers. Often this research simply treats the entrepreneurs as objects and not as subjects who actually have unique perspectives and understandings of entrepreneurship. This perspective, as well as the richness of entrepreneurs' lived experience, which drives them to be active as entrepreneurs, is missing from many research studies. In fact, this lived-experience could be the focus of a scientific study, since people can learn from firsthand experiences with starting and running an enterprise or firm.

A traditional, classical research method such as the quantitative approach is not sufficient to study this lived experience. In the quantitative method, the richness of entrepreneurs' experience is narrowed down into limited variables. Entrepreneurship is approached partially, and the wholeness and the context of the entrepreneurship are abandoned. As a result, the essence of the lived experience vanishes. The quantitative method thus leads to the absurdity of entrepreneurship, and diminishes its richness. 
Actually, there are many aspects of entrepreneurship to be studied, such as the role of capital, ability to evaluate opportunities, innovative attitude and lived experience. Each aspect of entrepreneurship needs a different method.

According to Schindehutte et al. (2006), entrepreneurship is a process of the inner struggle of an entrepreneur. Those processes and inner-self struggles, which are part of their lived-experiences, are not covered in most researches.

This paper will argue for the use of the phenomenological method in the study of entrepreneurship.

\section{Phenomenology as a research methodology}

Phenomenology is a term commonly used in philosophy. It is considered a current in philosophical thinking, which was very influential in Europe in the 20th century and changed the way people looked at a reality. Giorgi (2010) claims that to attempt to understand phenomenology apart from philosophy will lead nowhere. She adds that phenomenology comes from philosophy and should be understood from the philosophical point of view.

Phenomenology emerged as a response to rationalism, which cannot answer the problem of whether there is anything outside the human activity of thinking. Nor can it determine whether an intellectual truth is a single truth, whether a logical conclusion is identical to a factual truth, or whether is it possible to build knowledge regardless of personal experience. It does not address the idea that that our current knowledge and understanding is actually the result of deep processes that arises from our experience.

Phenomenology is also a critique of positivism, which strongly emphasises experience and senses, and so cannot answer the problem of science, which questions whether reality is an illusion. Does reality have its own existence, or does it exists only in the human mind through our consciousness?

Phenomenology emerged as a reaction to the chaotic conditions in Europe after the world wars. The destruction of social order caused profound uncertainties, and ideologies, values and culture became vague. Many people lost their orientation [standard?] of living, and fell into despair (Groenewald, 2004).

In such condition, the mathematician Husserl came up with his brilliant idea which introduced a new way of looking at a reality. For him, there was no such thing as the exact. He criticised mathematics, which could not guarantee a true and deeper knowledge. According to him, counting and measuring were only related to empirical things. The essence of objects which were known empirically could not be measured. For him, the ultimate and unconditional truth was always related to the things which transcended the mathematical science and calculations. Mathematical truths were a temporal truth and needed to be verified. We need to go deeper of the appearance of the thing to reveal its essence. To do this, we have to take away our presumptions and focus on the thing itself. We have to undergo a reduction process, which is to leave behind all our presupposition, assumptions, concepts or ideas. This is called bracketing, or epoche. The existence of the natural world is not denied; the point is that the world could not present itself without human consciousness. What objectively exists cannot be separated from a subject who recognises it.

Science did not arise from fact which was separate from those who experienced it; science arose from phenomena which presented themselves to human beings as avenues 
for further exploration. Outside reality could only be accessed via the knowledge by a subject actually experiencing it.

Hammond (Cope, 2010) expands the idea that phenomenology should be the basis of a science, since science grew and expanded from human experiences. He adds that science did not drop from the sky, but has undergone through a searching and proving process based on human experience.

Phenomenology is defined as a logical interpretation of certain phenomena (Sokolowski, 2000). Berglund (2008) describes it as something that appears in our minds. Moustakas (1994) adds that the core of phenomenology is to reveal the essence of the things. This is because the appearance of a thing does not yet reveal its identity; we still need to identify it. Appearance is different from its essence. Spinelli (2005) adds that the real identity or essence of the appearance needed to be explored deeper.

Moustakas (1994) writes that through the appearance of a thing, the researchers will be motivated to look for and find its essence. So what appears becomes the gateway for researchers to fully and deeply disclose the true realities of the things. The process of deeply entering to the things is called the ideatic process of using the bracketing or epoche technique. Into order to know things, people should have consciousness, and consciousness implies intentionality, since those who are conscious about a thing must have the intention to [know?] it. Consciousness and intentionality are only possible through human senses. The role of humans, specifically their experience, is essential to understand a thing more deeply. It is through humans that a thing is recognised and understood.

Phenomenology is different from positivism in that phenomenology considers reality as it appears in people's minds. Reality may stand alone, separated from human consciousness; people perceive reality because they are aware of its presence. Therefore, reality is recognised because there are human beings who acknowledge it. However, in order to recognise the essence of a thing or reality, we have to [bracket? Perhaps 'frame'] all our understandings and assumptions about the reality. It means we have to put our supposition [between the brackets]. Positivism, in contrast, considers reality as it is; the existence of reality does not depend on humans' awareness or consciousness.

Presently, there are many people using phenomenology as a research method [in entrepreneurship? I thought this method was not being used frequently - perhaps clarify this?]. To be applied as a research method, phenomenology, which is basically philosophical in nature, should be transformed to suit a scientific approach. This research method is heavily scientific. Science and philosophy have their own ways and principles, as well as valid arguments for understanding the world. Phenomenology as a philosophy thinking involves the use of speculative ways of thinking in an attempt to explain and understand the world. In contrast, science, as positive way of thinking, involves the use of experimentation, pragmatics, and rigid methodology to explain the world. To take phenomenology as a research method means transferring the philosophical thinking of phenomenology to the scientific method. Phenomenology already in use as a research method is sometimes called scientific phenomenology. Katadae (2011) writes that philosophy on the one hand is similar to science, but on the other hand is different. They are similar because both search for truth based on knowledge rather than opinion, yet different because one key characteristic of philosophy is the use of speculative ways of explaining the world. Philosophy relies on rationality and systematic thinking, and focuses holistically on the range of human experiences. 
Unlike philosophy, science only emphasises a specific part of such experiences. Science is limited to the physical world, while philosophy places less emphasis on the physical [is this change correct?] and delves more deeply into other aspects such as justice, values, motivation, belief, spirituality and meaning.

Science is value-free, while philosophy is attracted to personality together with human values. In science, human experiences get less attention, and humans are simply considered as living creatures. The quantity aspect of people is more highly regarded than their quality, and the experiential aspects are not observed. That is why science always fails to know and understand human beings' potential to interpret and give meaning to their world. That is why Giorgi (2000) writes that, in order to understand human experiences, we do need a special method and that is the phenomenological method.

Giorgi (2010) adds that phenomenology which has already been transformed and modified to be a methodology applied to science is called scientific phenomenology or applied phenomenology. She observes that phenomenology has been sustained because it can be transformed into a research method which could be used in conducting scientific research

The phenomenological method is used to study human experiences, and to understand and uncover the essence of those experiences. The experiences which such study targets are not merely experiences, but ones which are quite dynamic, flamboyant, alive, vital and important. So phenomenology does not deal with ordinary experience.

Phenomenology as a research method is considered as a response to psychology, which uses a positive empirical approach to the study of human beings. Human beings were previously considered only as physical entities, like any other entity, while other aspects such as justice, motivation, values, motivation, spirituality, belief and meaning, which make people significantly different from other creatures, are less considered. Those values which actually make people human function as of human action. Any human activity is actually a manifestation of what they are thinking of, planning on and aspiring to, which for them has meaning and value. As a research method, phenomenology offers a new way of looking at and understanding human actions.

Phenomenology as a research method has similarities with other qualitative research. Phenomenological method is part of qualitative method which emphasises understanding rather than proving a causal relationship. The data is in form of words rather than numbers. Data collection consists of in-depth interviews, where the researcher acts as a research instrument. It is descriptive in nature, since the objective is to gather detailed information. The more detailed the data, the better the reader may understand and put themselves in that context. Because this research is contextual in nature, the participants' environment should be carefully constructed so the readers will have an exact understanding of the context.

What is involved in phenomenological research? Those involved in this type of research are called participants. They provide information which is collected via in-depth interviews. They are not respondents, as in quantitative research; respondents simply respond to the questionnaire where the questions and answered are already prepared the researcher; hence respondents do not have any options.

Participants play an active role in the research. The information used by the research is exclusively provided by the participants themselves; their stories comprise the main data. . Participants should have experiences which researchers can study; he researchers should put away their assumptions about the research objects (bracketing) and use the ideatic process to uncover the essence of these experiences. The essence of the lived 
experience constitutes the research findings. As Van Manen (Katadae, 2011) writes, phenomenological research is the study of essence.

There may be questions about how far researchers should distance themselves from their opinions or assumptions about the research object. Finlay (2009) acknowledges that the researcher still has influence, adding that the influence of the researcher should be as minimal as possible, always self-critical and always maintaining an awareness of how far their subjective involvement affects the data. The researchers should ask themselves on how far they give effect to the participants' information during the interview. In phenomenological method, the researcher should have a phenomenological attitude that is an attitude which is not going to influence the participants.

Ashworth (Finlay, 2009) claims that there are a minimum of three important points in data gathering. First, the participants' information is not affected by theories, knowledge or other scientific reasoning. The pure experiences of the participants are the source of data. That experience should be their own lived experience in their daily lives. Second, the participants' information is not in form of a right or wrong answer. Third, the researchers' opinions should be put aside.

\section{The phenomenological method in entrepreneurship}

The experience of entrepreneurs, especially those who are successful in business, can greatly benefit others. People who learn from successful entrepreneurs will be encouraged to do more and not give up easily when facing tough business competition. Sharing the experiences of successful entrepreneurs constitutes valuable data.

The phenomenological method is the right method to analyse participants' lived experiences using a holistic, contextual and in-depth approach. The researchers start from the real experience rather than artificial assumptions.

In some quantitative research on entrepreneurship, the real lives experience of business practitioners get lost amid statistical numbers. The outcome of a quantitative method of entrepreneurship only confirms existing theories. Many times these results do not necessarily match the contextual settings of the people and society.

In the case of entrepreneurship, the results of research are sometimes strange for the entrepreneurs. What is believed and practiced deviates from the research results because the experience aspect of the agent is neglected.

There is a big gap between scientific and academic theories and reality as it is experienced. The quantitative method only examines reality partially and not wholistically. Researchers divide reality into several variables and analyse their causal effects by firs setting a hypothesis which most of the time does not exist in the real world. By Grave (Neergaard and Ulhoi, 2007) writes that research results using the quantitative approach often produce the same research results rather discovering than anything new. He adds:

I have been reading recent articles in leading entrepreneurship journals, and finding 'nothing much, really'. In one case, I found a lot of (potential) harm. I have not yet found one article that makes 'all the different in the world' and only a few that have given me even a glimpse of 'some good' ... most authors did not write even one sentence linking their findings to entrepreneurship practice, from which it might be inferted that most researchers are indifferent to the practical applications of their work. [Neergaard and Ulhoi, (2007), p.25] 
The fact that quantitative research will produce the same research outcome is difficult to prevent, since it simply confirms existing theories. This stands in sharp contrast to the phenomenological method, which can and does make new discoveries, because the different contexts and experiences will produce different findings.

Every entrepreneur has their own unique experience in doing business. Their different educational backgrounds, socio-economic and political contexts, values and cultures, visions, ideas, concepts and ambitions will influence the ways of doing business. Those experiences are rich and varied. An entrepreneur who is successful in one place might not automatically be successful in other places because of the different context. This shows the nature of science and knowledge which continue to grow according to the place, space, and time. Science is always dynamic, constantly developing and changing.

The phenomenological method introduces an alternative way of doing research which focus on the essential meaning of entrepreneurs' lived experience. The participants of the research are those who have those experiences. The credibility of the data is justified by the participants who have their authentic and legitimate own experience (Patton, 2002). The information comes directly from the participants themselves through in-depth interviews. The researcher is the instrument of data collection. During the interview, the researcher can dig deeper to learn information because they can think and speak. This is different from quantitative research, which uses questionnaires as data collection with limited options for answering, because the questions and answers have already been determined by the researcher. In qualitative research such as the phenomenological method, the data comes solely from the participants. When the participants tell their stories, they are telling their own lived experience. They uncover their own reality, meaning and understanding.

The data of the participants are treated as raw data. The role of the researcher is to process the story (data) so it has scientific meaning and can be understood by entrepreneurial scientists. There may be differences between participants' daily lived experience and what appears to be scientific meaning. Because the participants are not scientists, they have the raw data. So the role of the researcher is find scientific meaning in this data.

Entrepreneurship is emerging as an economic issue, so it is part of the economic discipline. It is heavily discussed in economics and management science. In economics and management, entrepreneurs are discussed in relation to business planning, opportunity identification, its relation to price theory, leadership, and other factors that affect entrepreneurs such as culture, values, and ethics. Because entrepreneurship relates to personality development, personal attitude and behaviour as well as motivation, it becomes relevant to many different disciplines. Every discipline focuses on specific aspects of entrepreneurship, but all those factors cannot sufficiently explain entrepreneurship. Those factors do not sufficiently explain why there are people who are successful and others who fail. Why there are different concepts of entrepreneurship amongst entrepreneurs? How do they consider success or failure? What are the values of being an entrepreneur?

This is why some scientists think there must be something deeper in entrepreneurs' consciousness that drives them in doing business. There must be some driving forces that encourage them to start and sustain in their venture. To know and understand this force, researchers should go deeper into entrepreneurs' consciousness, which can be revealed by interview. It is impossible to start the study by developing assumptions. Researchers will be able to discover the essence of entrepreneurs' unique experiences by putting aside 
their own assumptions and opinions. $\mathrm{Xi}$ add that in order to understand the consciousness and go deeper and reveal what is driving them to have such consciousness and awareness is an important factor in understanding entrepreneurship. Furthermore, entrepreneurship should be understood personally, directly from the individual entrepreneurs themselves. Drucker writes that entrepreneurship is not merely an economic issue but also a philosophical issue, since it relates to understanding people's consciousness. Bjerke (2007) adds that philosophy is the main basis for understanding entrepreneurship. He believes that entrepreneurship is related to the courage, a strong will, and eagerness to learn from experience. So it is not merely about business planning or financial benefit (Racine, 2009).

Carsrud and Brannback (2009) claim that entrepreneurship is a pre-paradigmatic discipline, so it is not suitable to use quantitative methods which require the use of full-fledged and approved theories. The multifaced approach to entrepreneurship indicates that there is no unifying theory on entrepreneurship. Casrud and Brannback (2009) add that there are some theories on entrepreneurship, but all of them are based in an externally oriented theoretical approach. There is a suspicion that many management theories are being forced to apply to the study of entrepreneurship.

Why is the phenomenological method suitable for entrepreneurship? According to trait theories, an entrepreneur is an individual who has strong motivation to materialise his or her eagerness. But this motivation is not always related to the economic aspect; there are many other factors that drive someone to start his or her venture and becoming an entrepreneur. Motivation itself is always a complex matter and it can only be understood by asking people who experience it directly. Motivation cannot be understood by setting up hypotheses and artificial assumptions of the causal effects of certain variables. Motivation is something inside a person, very personal and individual, and can only be understood by using a personal approach, such as interviews.

Bandura [Racine, (2009), p.39] states that, according to the self concept theory, every single person will act based on his or her personal factors. They are the only ones who know the motivation of their actions. Covey [Racine, (2009), p.67] adds that personal actions always centred on certain principles and values. Understanding these principles and values is very important for a researcher to know their inner motivation. Principles and values will form their characters and becoming the basis of every action. Principles and values also correlate to meaning. Entrepreneurs will do something because they are able to see the meaning of their actions. Principle and meaning do not always have economic nuance. Frankl (1997) writes that the main motivation of human action is to look for and discover meaning and not necessarily desire or power. This meaning will make people survive and thrive. Meaning arises and flourishes because of recognition and understanding. The study of and research on entrepreneurship is only possible if it aims to uncover the meaning possessed by the entrepreneurs themselves and by directly involving their lived experience. Through this directly link to the lived experience of the entrepreneurs, the researcher can understand the meaning of their actions in doing business. That is why the phenomenological method is very appropriate in doing research on entrepreneurship because it uncovers the meaning of being an entrepreneur.

This method is also very compatible with entrepreneurship because the subjective aspect of the entrepreneurship, which very much determines success or failure in business, is not merely a financial performance. Satisfaction and a sense of success are 
subjective in nature. This subjectivity sometimes makes the entrepreneur act illogically or irrational. Bjerke (2007) writes:

\begin{abstract}
I have become increasingly convinced that a logical-empirical, explaining type of research is not enough to move our knowledge of entrepreneurs forward to any major extent in many situations. This approach will often not do justice to what entrepreneurship and entrepreneurs are all about. Entrepreneurship belongs to the whole of society, not only to its economy, and entrepreneurs do not, most of the time, behave logically and relationally in any objective sense. On many occasions (maybe most) of our research efforts here, it seems, in my opinions, wiser to use a more interpretive, qualitative, understanding research approach. (p.1)
\end{abstract}

He adds that in the modern society, understanding is more suitable than explanation. According to Dilthey (Tool, 2007) that explanation is fit for physics, while understanding is appropriate for social science.

\title{
4 Phenomenology as qualitative method
}

The phenomenological method is qualitative because its main aim is to uncover the meaning of human experience, since every single experience has special meaning. Those experiences cannot be approached using the quantitative method. The data is in form of words which are gathered through in-depth interviews. The instrument of data gathering is the researcher him or herself. In this approach, reality is considered as a whole and not partially. Reality is believed to have connections with other things around it, such as society, economics, culture, politics, etc. Reality does not stand alone; context is also a very important consideration.

The focus of phenomenology is to understand what constitutes the everyday, intersubjective world. According to Husserl, we only know what we experience. The main objective of this method is to reveal the essence of that experience. The information comes exclusively from the participants, since their own experiences constitute their reality. In the phenomenological method, the researcher should put away his or her preconceptions, opinions, and assumptions about reality (bracketing).

\section{Conclusions}

The phenomenological method aims to understand the world as experienced and expressed by the participants. This approach believes that every single person has his or her own perception about the world and reality. The essence of such lived experienced can be obtained by non-interference from the researcher, which is called epoche (bracketing). Researchers should be fully aware of their prejudices, opinions, and preconception, so that these will not influence the participants.

The phenomenological method can be a good vehicle to illuminate and clarify important issues in entrepreneurship. Every single entrepreneur has his or her own understanding of being an entrepreneur. Each of them has their own conceptions, ideas, and opinions about entrepreneurship. Their lived experiences will determine their way of doing business. Their experiences are unique and can become a source of knowledge for others who are involved in entrepreneurship. 


\section{References}

Berglund, H. (2008) Researching Entrepreneurship as Lived Experienced, pp.75-76 [online] http://www.henrikberglund.com/Phenomenology.pdf (accessed 24 September 2010).

Bjerke, B. (2007) Understanding Entrepreneurship, Edward Elgar Publishing Limited, Linnaeus University, Sweden.

Carsrud, A.L. and Brannback, M. (2009) Understanding The Entrepreneurial Mind, Springer, Lancaster.

Cope, J. (2010) 'Entrepreneurial learning from failure: an interpretative phenomenological analysis', Journal of Business Venturing, Vol. 26, No. 6, p.20.

Djalal, D.P. (2011) The Jakarta Post, 23 August, p.3.

Drucker, P. (1984) Innovation and Entrepreneurship, Practice and Principles, Perfect Bound, New York.

Finlay, L. (2009) 'Debating phenomenological research methods', Phenomenology \& Practice, Vol. 3, No. 1, pp.6-25.

Frankl, V. (1997) Man’s Search for Meaning, Beacon Press, Boston.

Giorgi, A. (2000) 'The status of Husserlian phenomenology in caring research', Scandinavian Journal Caring Science, Vol. 14, No. 1, pp.3-10.

Giorgi, A. (2010) 'Phenomenology and the practice of science', Existential Analysis, 1 January, Vol. 21, No. 1, pp.3-22.

Groenewald, T. (2004) 'A phenomenological research design illustrated', International Journal of Qualitative Methods, Vol. 3, No. 1, pp.1-26.

Katadae, A. (2011) 'Phenomenological understanding of the meanings in the Life world: bridging philosophy and research methodology', OLIVE Kagawa University academic information repository, pp.11-19 [online] http://www.shark.lib.kagawau.ac.jp/kuir/file/1095/AN00038237_131_11.pdf (accessed 5 August 2012).

Langley, K. (2011) 'Entrepreneurial spirit', The Jakarta Post, 22 July 2011, p.28.

Moustakas, C. (1994) Phenomenological Research Methods, Sage Pub, Thousand Oaks, California.

Neergaard, H. and Ulhoi, J.P. (2007) Handbook of Qualitative Research Methods in Entrepreneurship, Edward Elgar Publishing Limited, UK.

Patton, M.Q. (2002) Qualitative Research and Evaluation Methods, 3rd ed., Sage Pub, Thousand Oaks, California.

Racine, W.P. (2009) A Qualitative Study of Motivations and Lived Experiences: New Venture Creation of Environmental Entrepreneurs in Ohio, DisertasiDoktor, Capella University.

Schindehutte, M. et al. (2006) 'Beyond achievement: entrepreneurship as extreme experience', Small Business Economics, Vol. 27, pp.349-368 [online] http://www.link.springer.com/article/10.1007\%2Fs11187-005-0643-6\#page-1 (accessed 2 September 2011).

Sokolowski, R. (2000) Introduction to Phenomenology, Cambridge University Press, New York.

Spinelli, E. (2005) The Interpreted World. An Introduction to Phenomenological Psychology, Sage Pub, London.

Tool, A. (2007) 'Wilhelm Dilthey on the objectivity of knowledge in human sciences', Trames, Vol. 11 (61/56), No. 1, pp.3-14. 